\title{
Journal of French Philosophy
}

Bulletin de la Société Américaine de Philosophie de Langue Française

\section{EDITORIAL CORRESPONDENCE:}

Editorial correspondence should be sent to Diane Perpich, Department of Philosophy \& Religion, Hardin Hall 126D, Clemson University, Clemson, SC 29634 (dperpic@clemson.edu) and Daniel Smith, Department of Philosophy, BRNG 1360, Purdue University, West Lafayette, IN 47906 (smith132@purdue.edu).

\section{BOOK REVIEWS:}

Proposals for reviews of recent books should be sent to the book review editor, Dana Hollander, Department of Religious Studies, University Hall 109, 1280 Main Street West, Hamilton, Ontario, L8S 4L8 Canada (danahol@mcmaster.ca).

\section{GUIDELINES FOR AUTHORS:}

Manuscripts in French or English will be considered. Manuscript submissions should follow Chicago Manual of Style guidelines. Authors are asked to submit one printed copy, a disk version (in Word or Rich Text Format), and a 200 word abstract. Electronic submissions will also be considered (paper plus abstract). Submissions may be sent to either of the coeditors at the addresses given above for editorial correspondence.

\section{ADVERTISING:}

The Bulletin accepts advertising. For information and current rates contact SAPLF, Department of Philosophy \& Religion, Hardin Hall 126D, Clemson University, Clemson, SC 29634. 